\title{
Spiritual Health in Nurses, Nursing Faculties, and Nursing Students of Jahrom University of Medical Sciences, Iran
}

\author{
Mahboobeh Taghizadeganzadeh ${ }^{1}$, Zahra Shadfard $^{2}$, Mohammad Ali Montaseri $^{3}$ \\ Fajrieh Zahedinia ${ }^{4}$, Zahra Karami ${ }^{5}$ Zahra Pishgar $^{6}$
}

\begin{abstract}
Background \& Aims: Spiritual health is an important aspect of health, which shows the good relationship of an individual with God and a sense of harmony between himself, God, and life. Nursing profession is associated with numerous stressful encounters in the workplace, such as death and illness. Nurses, nursing faculties, and students are the three main groups in this profession who could largely benefit from spirituality in personal, professional, and organizational dimensions. One of the main benefits of spiritual health in the nursing profession is the improvement of mental health and quality of care. The present study aimed to determine the status of spiritual health in the nurses, nursing faculties, and nursing students of Jahrom University of Medical Sciences, Iran.

Materials \& Methods: This descriptive study was conducted on 455 participants (268 nurses, 31 lecturers, and 156 nursing students) at Jahrom University of Medical Sciences in 2018. The participants were selected via census sampling. Data were collected using a comprehensive questionnaire to measure spiritual health in the Iranian population and a demographic questionnaire. The questionnaire consisted of 48 items and two cognitive/emotional (insight/orientation) and behavioral (performance) components. The total score of the questionnaire was 100 . The questionnaire was provided to the subjects by two research assistants and completed in a self-report manner after obtaining informed consent. Data analysis was performed in SPSS version 16 using descriptive statistics (frequency, frequency percentage, mean, and standard deviation) and analytical statistics (independent t-test, oneway ANOVA, and Scheffe post-hoc test).

Results: The mean age of the participants was $27.19 \pm 6.68$ years. The mean score of spiritual health was estimated at $79.89 \pm 11.87$, and achieving approximately $80 \%$ of the total score indicated the favorable spiritual health of the participants. In addition, the mean scores of the cognitive/emotional and behavioral components of spiritual health were $82.28 \pm 11.93$ and $75.45 \pm 11.99$, respectively. The mean score of spiritual health was $84.58 \pm 9.58$ in the nurses, $86.67 \pm 11.15$ in the nursing faculties, and $68.44 \pm 14.55$ in the nursing students. A significant correlation was observed between age and spiritual health $(\mathrm{r}=0.362)$. The mean score of spiritual health was significantly higher in women compared to men $(\mathrm{P}=0.001)$. The spiritual health of the participants with the work experience of more than five years had no significant difference with those with less work experience $(\mathrm{P}=0.507)$. Moreover, years of teaching had no effect on the spiritual health of the faculty members $(\mathrm{P}=0.57)$. Participation in spirituality courses also had no significant effect on the score of spiritual health $(\mathrm{P}=0.658)$. First-year students had higher a spiritual health level compared to the senior students $(\mathrm{P}=0.007)$.

Conclusion: In this study, the participants achieved nearly $80 \%$ of the total score, which indicated their favorable spiritual health status. It seems that the religious nature of the Iranian culture and the tendency to preserve spiritual values have been effective in achieving these results. The nurses in our study attained $84 \%$ of the spiritual health score. Since Islam is the main religion of the Iranian community, religious beliefs are an integral part of people's

\footnotetext{
1. Department of Operation Room, Nursing and Paramedical School, Jahrom University of Medical Sciences, Jahrom, Iran

2. Department of Operation Room, Nursing and Paramedical School, Jahrom University of Medical Sciences, Jahrom, Iran (Corresponding author) Tel: 09173920283 Email: zahrashadfard@jums.ac.ir;

3. Department of Operation Room, Nursing and Paramedical School, Jahrom University of Medical Sciences, Jahrom, Iran

${ }^{4}$. Department of Nursing, School of Nursing, Shiraz University of Medical Sciences, Shiraz, Iran

5 . Department of Nursing, Nursing and Paramedical School, Jahrom University of Medical Sciences, Jahrom, Iran

${ }^{6}$. Department of Anesthesiology, Nursing and Paramedical School, Jahrom University of Medical Sciences, Jahrom, Iran
} 
lives, and attention to the spiritual issues of patients is inevitable. This makes nurses more sensitive to the concept of spirituality, and they managed to achieve spiritual health as a result. According to the results, the nursing faculties also achieved $84 \%$ of the total score, which indicated that they are acceptable role models to their students and have great spiritual capacity to teach spiritual concepts. Meanwhile, the nursing students achieved approximately $70 \%$ of the spiritual health total score. Nursing students enjoy respecting, helping, giving hope, and supporting other, and such actions enhance their spiritually. Given the importance of spiritual health in nurses in personal, professional, and organizational dimensions, maintaining and promoting these values are of utmost importance. Therefore, the recognition of the factors with constructive or destructive effects on the spiritual health of nurses should be considered by authorities. Considering the favorable spiritual health of nurses and nursing faculties and their close interactions with nursing students, it is recommended that the spiritual capacity of nurses and nursing faculties be exploited through proper planning and teaching of spiritual concepts to nursing students. Furthermore, the integration of the concepts associated with spirituality in the nursing curriculum and providing executive guarantees for the teaching of these concepts by authorities are highly recommended. Efficient training courses should also be planned and implemented in the form of in-service training in order to promote the spiritual health of nurses and nursing faculties.

Keywords: Spirituality, Health, Nurses, Nursing Faculties, Nursing Students

\section{Conflict of Interest: No}

How to Cite: Taghizadeganzadeh M, Shadfard Z, Montaseri MA, Zahedinia F, Karami Z, Pishgar Z. Spiritual Health in Nurses, Nursing Faculties, and Nursing Students of Jahrom University of Medical Sciences, Iran. Iran Journal of Nursing. 2020; 33(126):16-27.

Received: 6 Jul 2020

Accepted: 5 Oct 2020 


\title{
سلامت معنوى در بر ستاران، اساتيد ودانشجويان ير ستارى دانشكاه علوم يزشكى جهرم
}

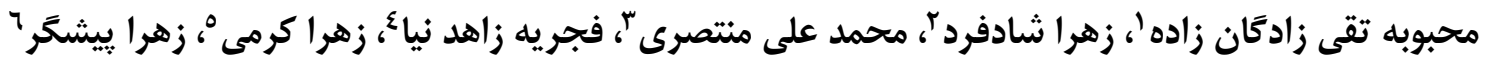

جوكيله

زمينه و هدف: سلامت معنوى رابطهى خوب فرد با معبود و احساس هماهنگى بين خويشتن، خدا و زندكى است. حرفه يرستارى با عو امل تنش زاى

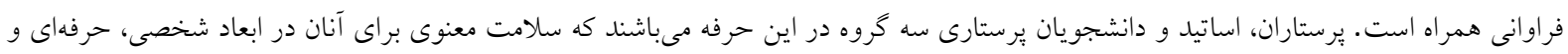

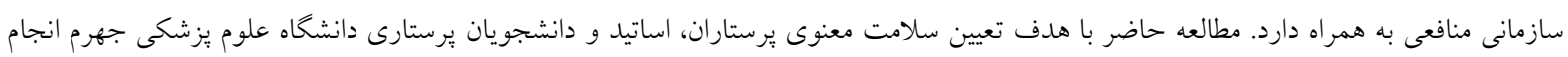
كرفت.

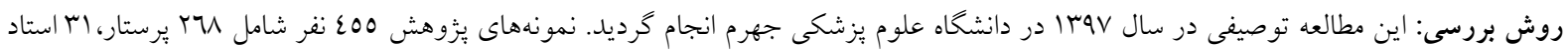

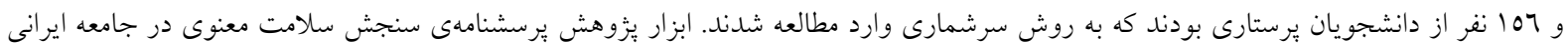

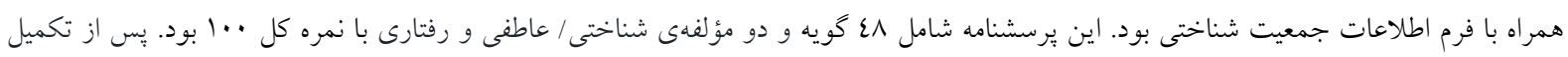

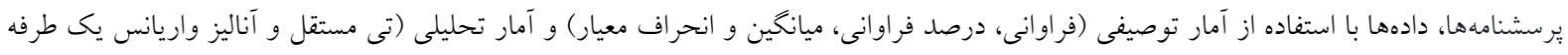

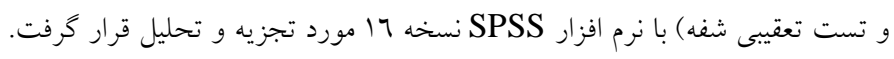

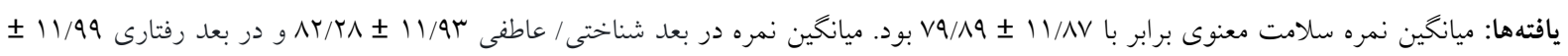

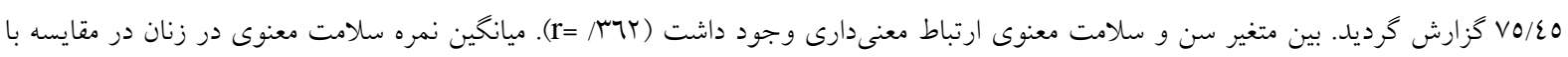

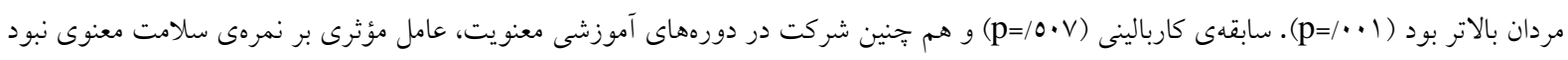
(p=/70V)

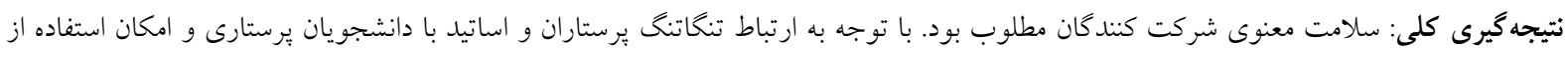

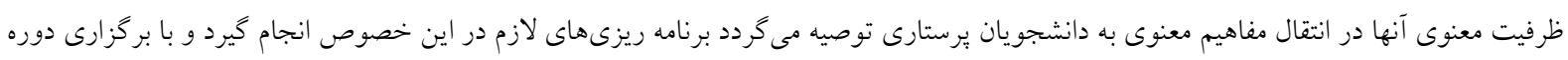
هاى آموزشى ضمن خدمت امكان ارتقاى سلامت معنوى در آنها فراهم كردد.

كليد وازهها: معنويت، سلامت، يرستاران، اساتيد برستارى، دانشجويان يرستارى

تعارض منافع: ندارد

تاريخ دريافت: 99/2/17

99/V/1 عاريخ بذيرش:

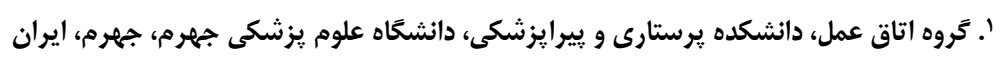

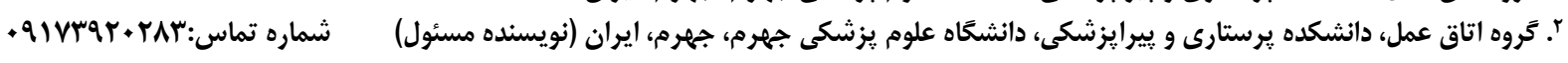
Email: zahrashadfard@jums.ac.ir

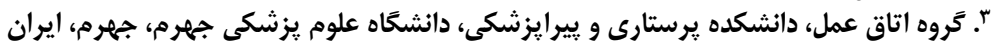

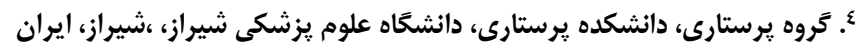

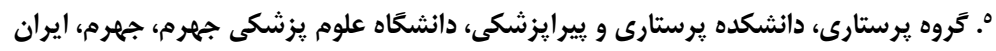

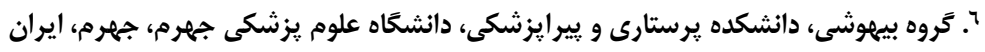


و نحرش مراقبتى آنان آثار مثبت داشته باشد به كونهاى كه

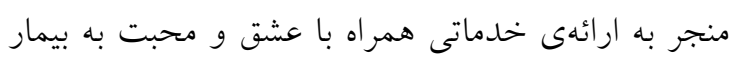

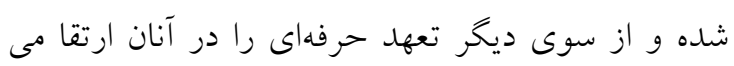

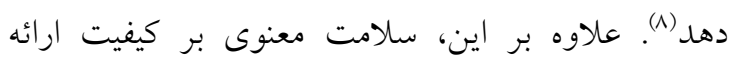

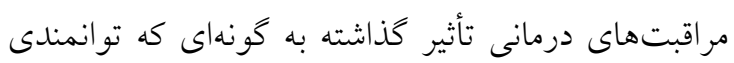

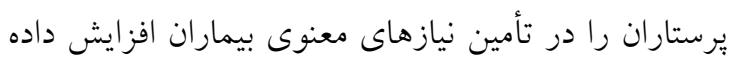
و به افزايش رضايتمندى بيماران كمك مى كند (v). بنابراين

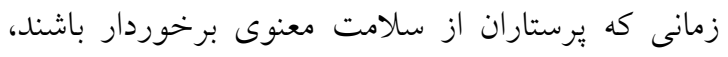

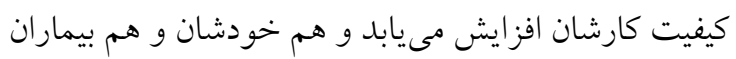

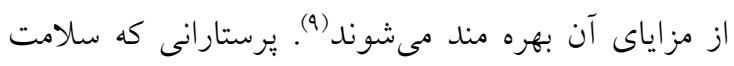

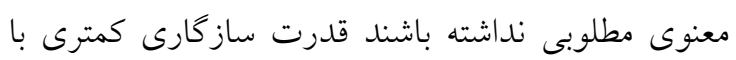

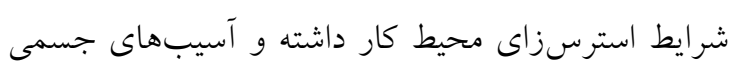

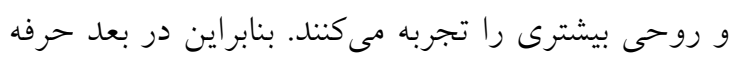

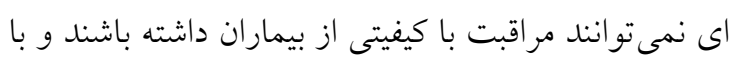
عدم تحقق اهداف سيستمهاى درمانى كارايى سازمان را بـان

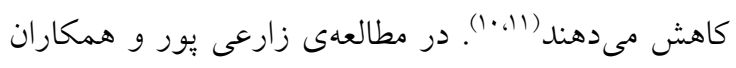
كه به منظور بررسى سلامت معنوى يرستاران در اروميه

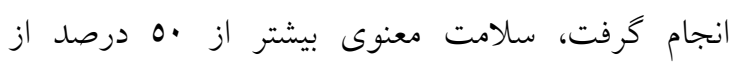

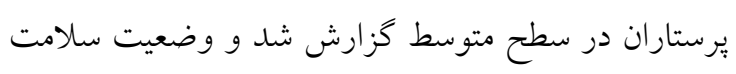

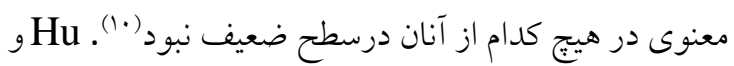

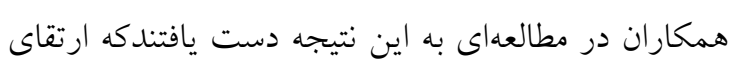

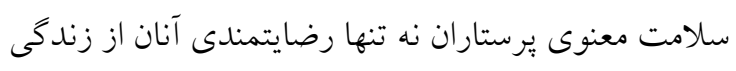

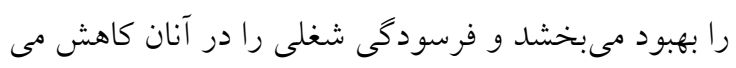

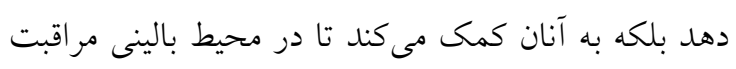

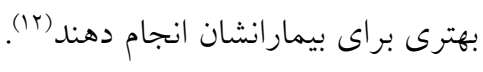

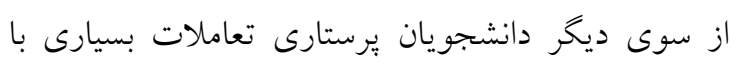

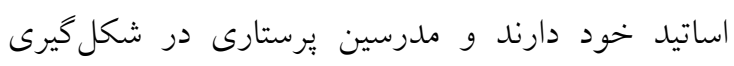
باورهاى معنوى، تشخيص و رفع نيازهاى معنوى بيماران

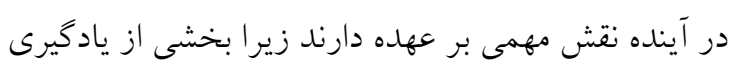

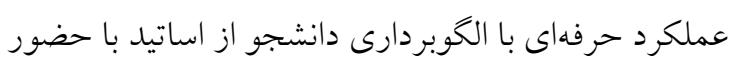

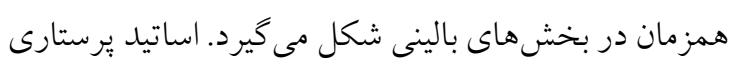

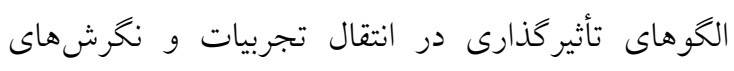
حرفهاى به دانشجويان هستند و رفتارهاى اخلاقى آنان

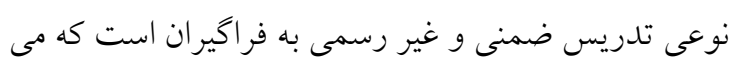

مقلهمه

سلامتى مفهومى است كه تمام جنبههاى جسمى، اجتماعى،

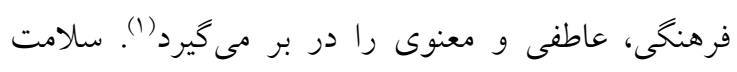
معنوى به عنوان هستهى مركزى سلامتى در انسان(r) و ورئي بيانخر رابطهى خوب فرد با معبود و احساس هماهنكى بين منين خويشتن، خدا و زندگى است (r). بر اساس آموزههاى اسلامى سلامت معنوى، سلسله مراتبى يويا است كه در آن بينشها، كرايشها و توانايىهاى فرد به طور هماهنخ در

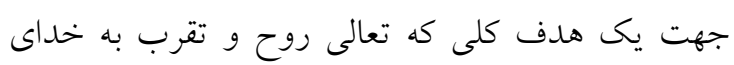
متعال است به كار كرفته مىشود و رفتارهاى فرد متناسب با آن ظهور مى يابد (ع). سلامت معنوى در تعاملات روزانه با ديخران به صورت عشق، اعتماد، صداقت، درستكارى، يكهيارجگى، احترام، فداكارى و دلسوزى تظاهر مى كند. دستيابى به آرامش درونى از بيامدهاى سلامت معنوى است إست

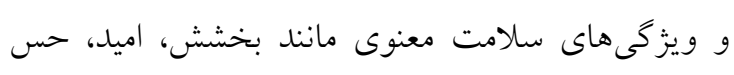

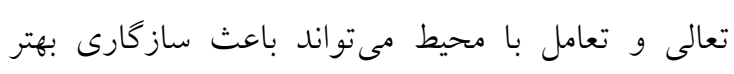

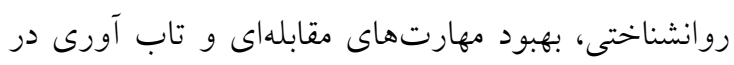
برابر فشارهاى روانى و در نتيجه بهزيستى در افراد شود (0). زمانى كه سلامت معنوى در انسان به خطر مى افتلد فرد

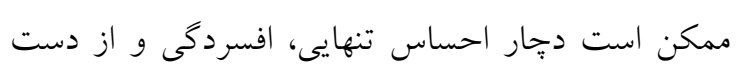
دادن معنا در زندكى شود (7). توجه به وضعيت سلامت معنوى در حرفهى يرستارى حائز

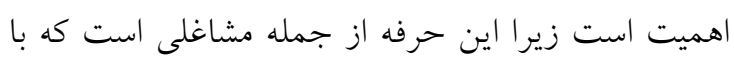
مشكلات و عو امل تنشزاى فراو انى در محيط كار همجيون مرگ، بيمارى، فشارهاى كارى، درگيرى هيجانى، ارتباط نزديك با بيماران، تقاضاى زياد در محيط بالين، كمبود

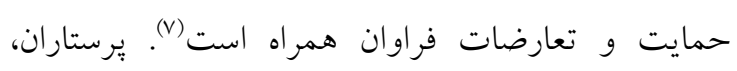
اساتيد و دانشجويان برستارى سه گروه اصلى در اين حرفه مىباشند كه برخوردارى از سلامت معنوى براى آنان در ابعاد شخصى، حرفهاى و سازمانى منافعى به همراه دارد. در بعد شخصى يرستارانى كه سلامت معنوى بيشترى دارند

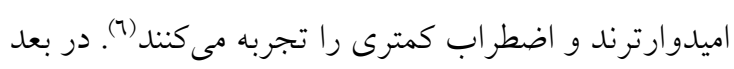
حرفهاى و سازمانى سلامت معنوى براى يرستاران سبب خلق نظام ارزشى و اعتقادى مى شود كه مىتواند بر عملكرد 


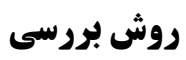

يزوهش حاضر يكى مطالعه توصيفى - مقطعى بود كه در برد

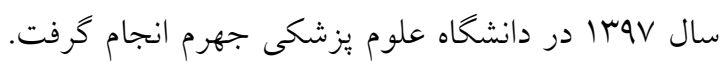

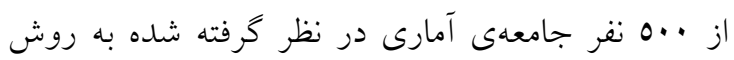

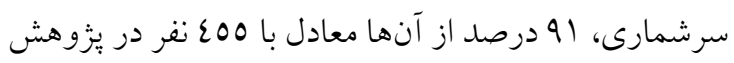

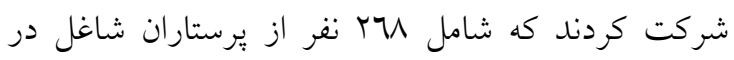

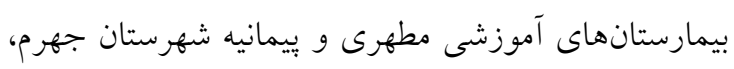

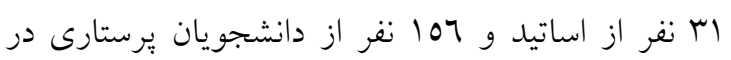

دانشكده برستارى دانشخاه علوم بزشكى جهرم بودند.

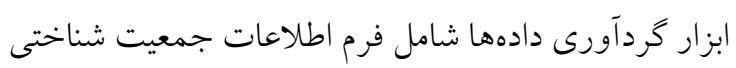
و برسشنامهى جامع سنجش سلامت معنوى در جامعاده

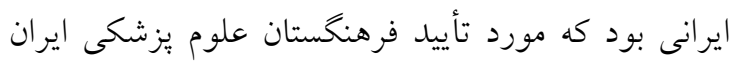
است (IV). فرم اطلاعات جمعيت شناختى ويزگكىهاى سن،

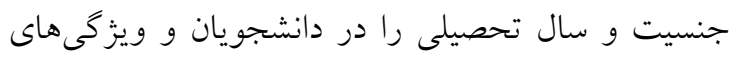

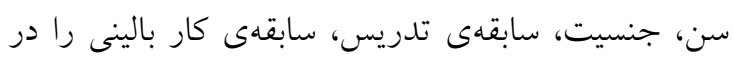

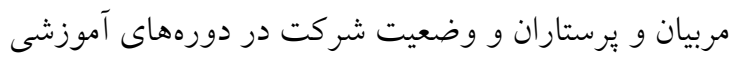

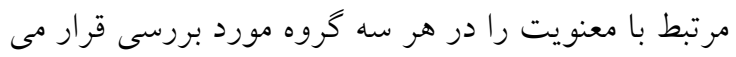

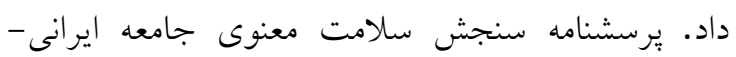

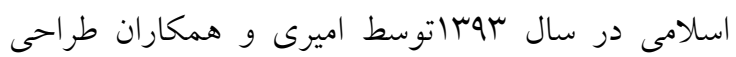

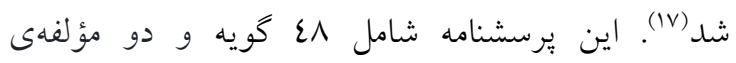
شناختى/ عاطفى (بينش و كرايش) و رفتارى (عملكرد)

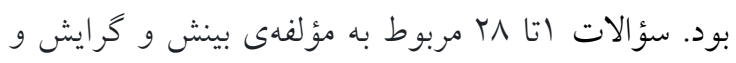

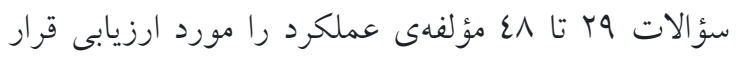

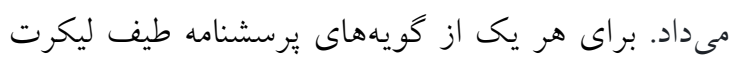

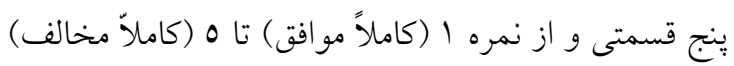

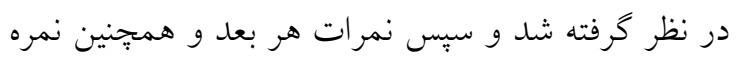
كل قرسشنامه در قالب · تا ..1 (كمترين نمره صفر و

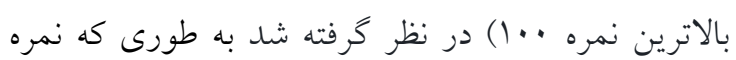
بالاتر نشان دهنده برخوردارى از سلامت معنوى بالاتر بود.

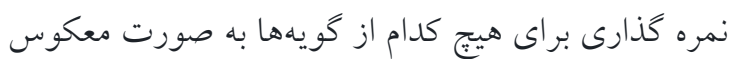

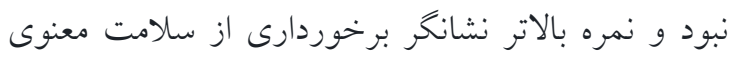

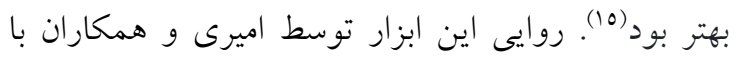

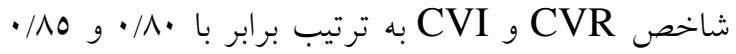

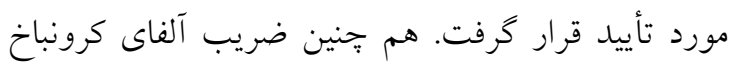

تواند موجب يرورش اخلاقيات در دانشجويان يرستارى

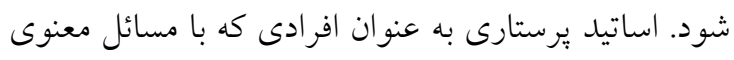

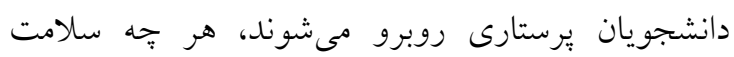

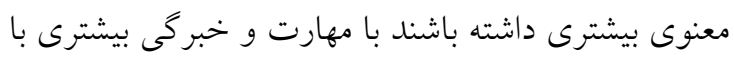

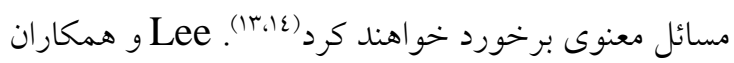
در مطالعهاى كه در سال عالبr در كشور كره انجام دادند

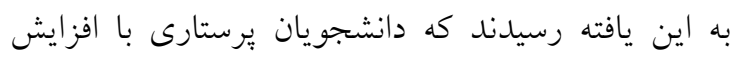

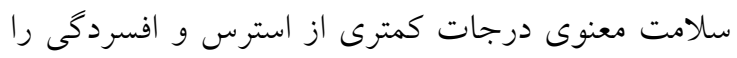

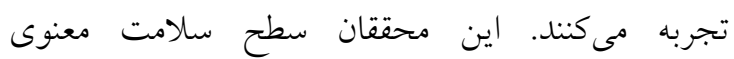
دانشجويان را متوسط ارزيابى كردند و بر اتخاذ سياست

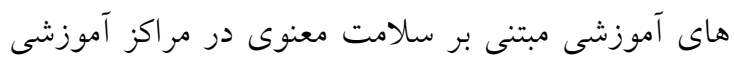
تأكيد كردند (10). در مطالعهى نصر الهيى و همكاران نتايج

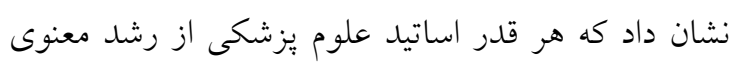
بالاترى برخوردار باشند در انتقال مفاهيم معنوى بـ ديه دانشجويان موفقتر عمل خواهند كرد (17).

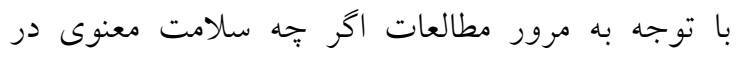

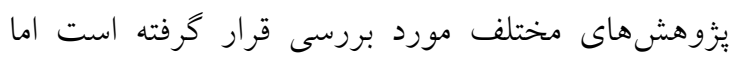

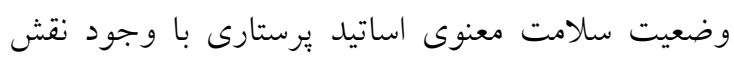
تأثير خذار آنها مورد غفلت واقع شده است و و از آن آن جايى

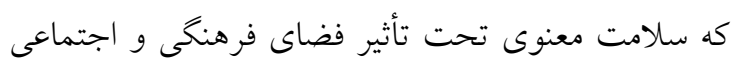

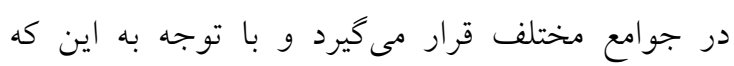

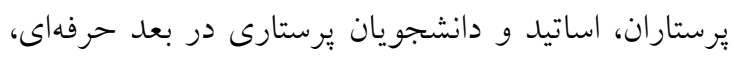

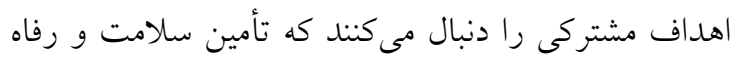

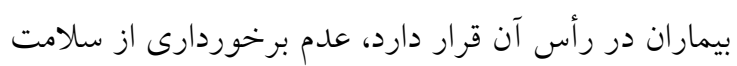

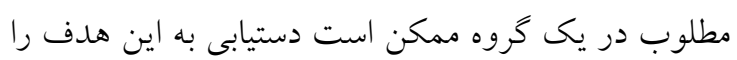

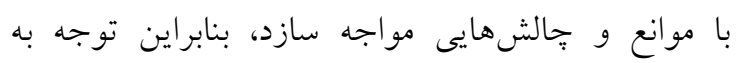
سلامت معنوى هر سه كروه در كنار يكديخر حائز اهميت

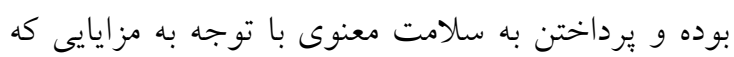

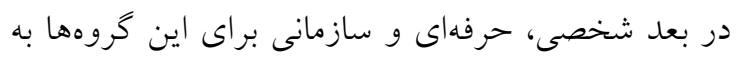

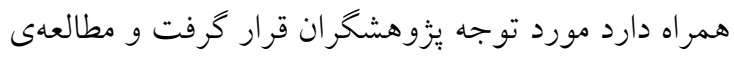
حاضر با هدف تعيين سلامت معنوى برستاران، اساتيد و

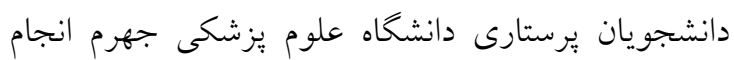
كرديد. - مري. 
كَرفت و پِس از كسب رضايت آكَاهانه از آنان، برسشنامه

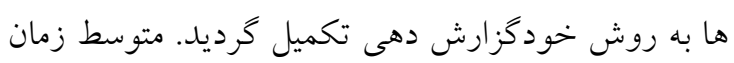

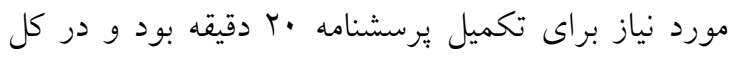

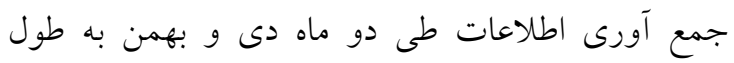

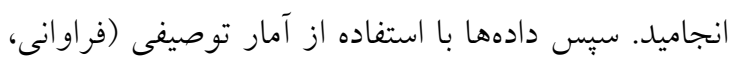

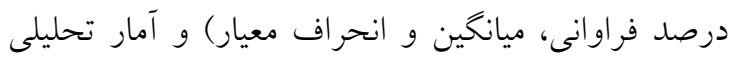

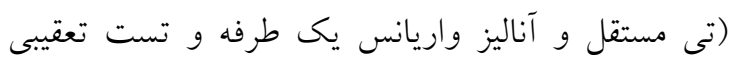

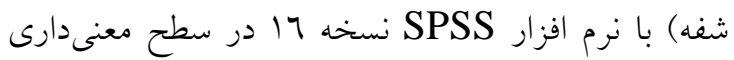

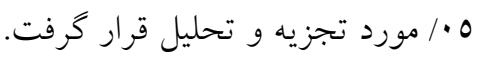

\section{يافتهها}

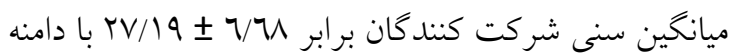

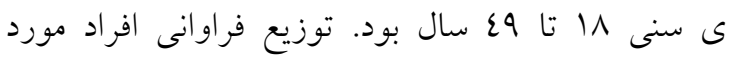
يزوهش بر حسب متغيرهاى جمعيت شناختى در جدول شماره ا آورده شده است.
بزركتر از ^/• و نتايج حاصل از روش آزمون-بازآزمون با

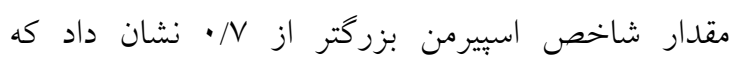

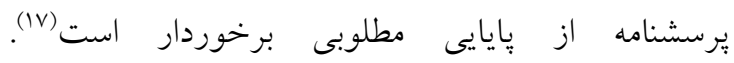

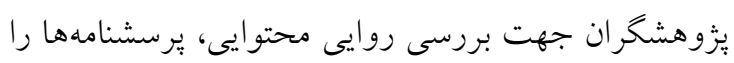

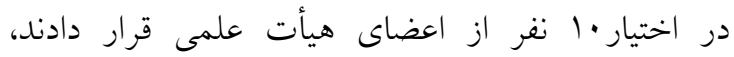

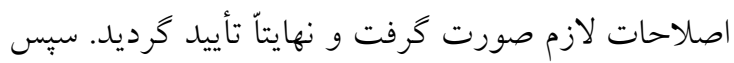

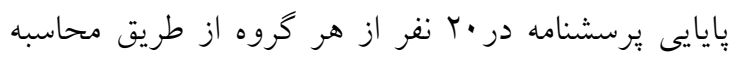

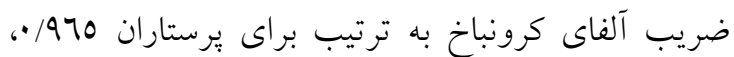

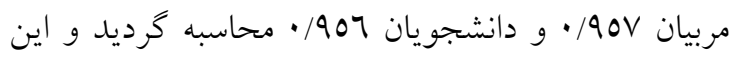
افراد از مطالعه حذف كرديدند. در مطالعات بيشين نيز از

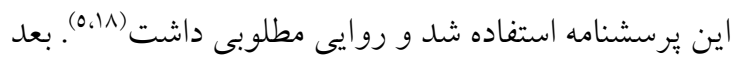

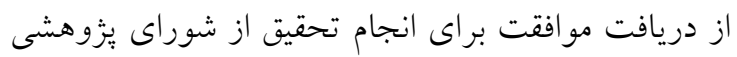

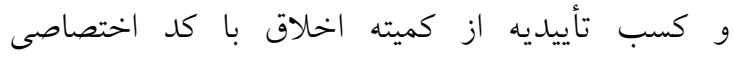

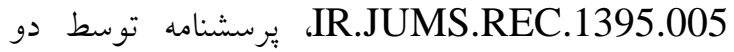

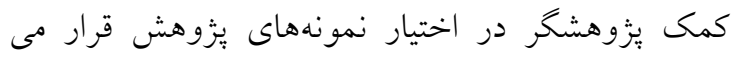

جدول شماره ا: توزيع فراوانى متغيرهاى جمعيت شناختى در افراد مورد يزوهش متش هاء

\begin{tabular}{|c|c|c|}
\hline فر اوانى (درصد) & \multicolumn{2}{|c|}{ متغيرهاى جمعيت شناختى } \\
\hline$(Y V / \Lambda) I V Y$ & 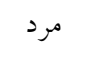 & جنس \\
\hline$(T r / T) Y \wedge r$ & زن ان & \\
\hline (VI) Kr & $0>$ & سوابق تدريس، سال \\
\hline$(Y q) 9$ & $0<$ & \\
\hline$(r q / \varepsilon) \| 1$ & $0>$ & سابقه كار بالينى \\
\hline$(7 \cdot / 7)|1|$ & $0<$ & \\
\hline ( & 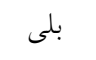 & كذراندن دوره معنويت \\
\hline$(\Lambda T / 1)$ rar & خير & \\
\hline$(\mid \Lambda) \Upsilon \Lambda$ & اول اول & \\
\hline$(r o / r) 00$ & 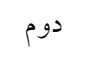 & سال تحصيلى \\
\hline$(Y \wedge / \Lambda) \varepsilon 0$ & 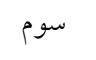 & \\
\hline$(\backslash \Lambda) Y \Lambda$ & جهارم & \\
\hline
\end{tabular}

كنند كان در حيطهى شناختى / عاطفى در مقايسه با حيطهى رفتارى از نمرات بالاترى برخوردار بودند به كونهاى كه

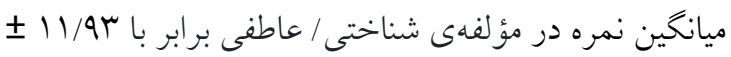

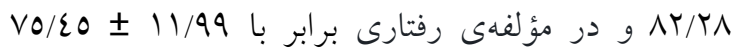
كزارش گرديد (جدول شماره ب).
ميانخين نمره كل سلامت معنوى برابر با VI/A9 I نشان داد كه شركت كنندگان با كسب حدود • • درصد از نمره كل از سلامت معنوى خوبى برخوردار بودند. ميانخين نمرات براى برستاران، اساتيد و دانشجويان به ترتيب برابر

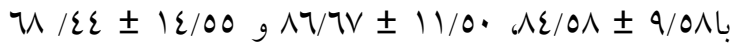
كزارش گرديد. نتايج اين مطالعه حاكى از آن بود كه شركت 
جدول شماره ז: ميانكَين سلامت معنوى و مؤلفههاى آن در كَروههاى مورد يزوهش

\begin{tabular}{|c|c|c|c|c|}
\hline 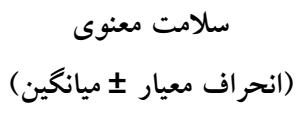 & 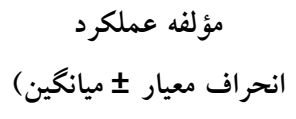 & 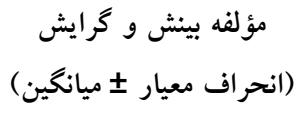 & (درصد & متغير \\
\hline$\wedge \varepsilon / 0 \wedge \pm 9 / 0 \wedge$ & $\vee q / \wedge 7 \pm 1 \cdot / \Gamma \wedge$ & $\Lambda V / r \pm q / r q$ & $\begin{array}{l}r 71 \\
(09)\end{array}$ & ير برستاران \\
\hline$\Lambda 7 / 7 \vee \pm 11 / 0$. & $11 / \cdots \pm 11$ & $q \cdot / \cdot \varepsilon \pm 1 r$ & $\begin{array}{c}\mu l \\
(7 / \Lambda)\end{array}$ & اساتيد \\
\hline$W / \varepsilon \varepsilon \pm 1 \varepsilon / 00$ & $70 / 0 \pm 1 \varepsilon / 7$ & $79 / 0 \pm 1 \varepsilon / 0$ & $\begin{array}{c}107 \\
(r \varepsilon / T)\end{array}$ & دانشجويان \\
\hline$\vee Q / \wedge q \pm 11 / \wedge V$ & $\mathrm{~V} 0 / 20 \pm 11 / 99$ & $\Lambda T / T \Lambda \pm 11 / 9 r$ & $\begin{array}{l}200 \\
(1 \cdots)\end{array}$ & كل افراد \\
\hline
\end{tabular}

نمره سلامت معنوى نبود (p=/OV). هم جنين نتايج نشان مىدهد كه شركت در دورهاى آموزشى معنويت، عامل مؤثرى بر نمرهى سلامت معنوى نبوده است (p) (p) و و سلامت معنوى دانشجويانى كه در سال اول تحصيل بودند به طور معنى دارى بالاتر از دانشجويان سالهاى بالاتر مى

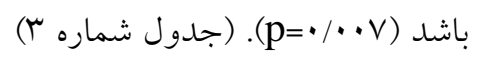

آزمون همبستخى بيرسون ارتباط مثبت و معنى دارى را بين دو متغير سن و سلامت معنوى نشان داد (r= (r= (r ). ميانخين نمره سلامت معنوى در زنان در مقايسه با مردان به طور معنى يرستاران و اساتيد با سابقه كار بالينى بيشتر از ينج سال اختلاف معنى دارى با افراد با سوابق كارى بايينتر نداشت (p=•/0•v)

جدول شماره س: نمرات سلامت معنوى بر اساس متغيرهاى جمعيت شناختى در افراد مورد يزوهش سلامت معنوى

\begin{tabular}{|c|c|c|c|c|}
\hline آزمون آمارى & p-value & ميانخين I انحراف معيار & \multicolumn{2}{|c|}{ متغير جمعيت شناختى } \\
\hline \multirow[t]{2}{*}{ ضريب همبستخى بيرسون } & $\mathrm{p} \leq \bullet / \cdot \cdot 1$ & $r V / 19 \pm 7 / 71$ & \multirow{2}{*}{\multicolumn{2}{|c|}{ سن }} \\
\hline & $r=\cdot \pi 7 r$ & & & \\
\hline \multirow[t]{2}{*}{ تى تى تست } & $\mathrm{p} \leq \cdots / \cdots 1$ & $V 7 / r \cdot \pm|\varepsilon / 9|$ & 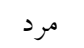 & جنسيت \\
\hline & $t=r / \mu \wedge$ & $\Lambda \cdot / 91 \pm 1 r / 0 \varepsilon$ & زن ان & \\
\hline \multirow[t]{2}{*}{ ت تى تست } & $\mathrm{p}=\cdot / 0\{1$ & $10 / 0 \mathrm{r} \pm 1 \cdot / 1 \mathrm{~V}$ & $0>$ & سوابق تدريس، \\
\hline & $\mathrm{t}=\cdot / 719$ & $\Lambda M / \cdot 0 \pm 9 / \cdot \Lambda$ & $0<$ & سال \\
\hline \multirow[t]{2}{*}{ تى تست } & $\mathrm{p}=\cdot / 0 \cdot V$ & $10 / \mu \cdot \pm 9 / \cdot 9$ & $0>$ & سابقه كار \\
\hline & $t=/ 770$ & $\wedge \varepsilon / \varepsilon \wedge \pm 11 / \cdot r$ & $0<$ & بالينى، سال \\
\hline \multirow[t]{2}{*}{ تى تست } & $\mathrm{p}=\cdot / 70 \mathrm{~V}$ & $V \Lambda / \Gamma \wedge \pm 1 T / Y 7$ & بلى بلى & كذراندن دوره \\
\hline & $\mathrm{t}=\cdot / \varepsilon \varepsilon \varepsilon$ & $V q / T V \pm \mid r / q \varepsilon$ & خير & معنويت \\
\hline \multirow[t]{4}{*}{ آنوا } & $\mathrm{p}=\cdot / \cdot \cdot v$ & $V 0 / 0 r \pm 1 \cdot / r q$ & اول & \\
\hline & $\mathrm{F}=\varepsilon$ & $7 \varepsilon / \cdot V \pm \mid r / 1 r$ & دوم & سال تحصيلى \\
\hline & & $\Psi / U \pm \| r / v$. & سوم & \\
\hline & & $v \cdot / \mu \Lambda \pm \| r / \mathrm{T}$ & جهارم & \\
\hline
\end{tabular}


وضعيت سلامت معنوى اساتيد يرستارى در ايران يافت

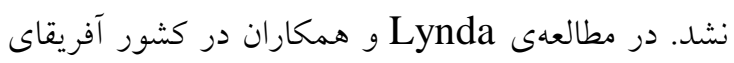

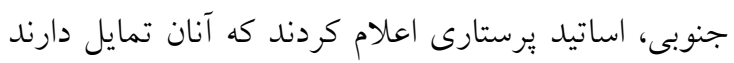

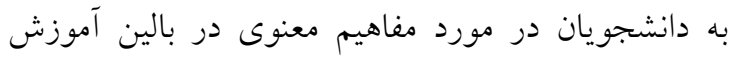

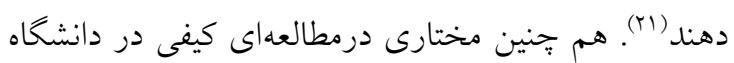

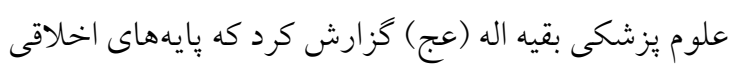

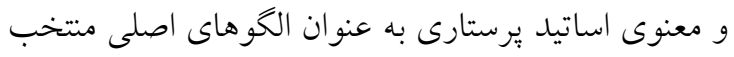
دانشجويان، يادكيرى مفاهيم معنوى را در دانشجويان

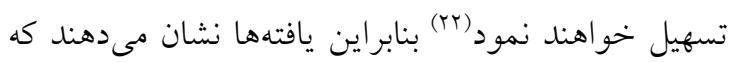

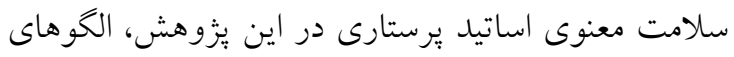

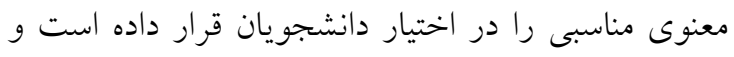

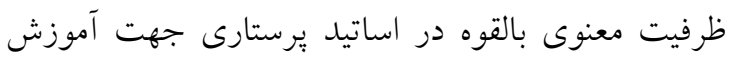
مفاهيم معنوى وجود دارد.

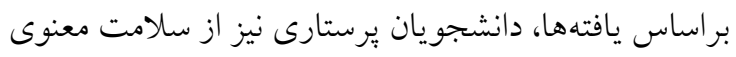

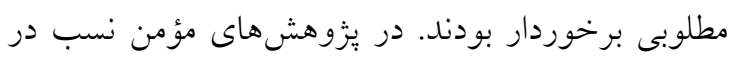

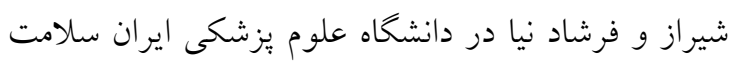

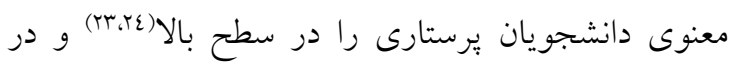

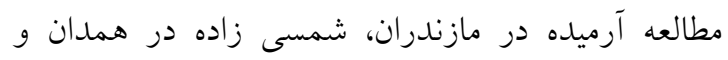
Hsiao

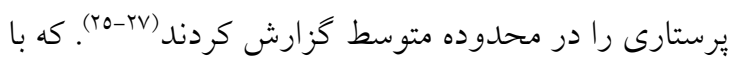

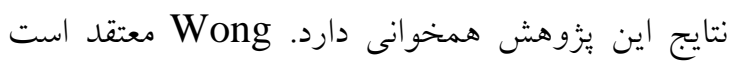

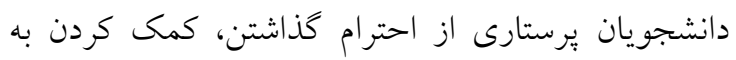

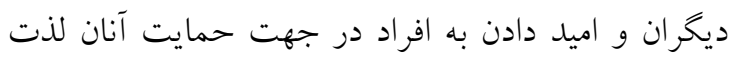

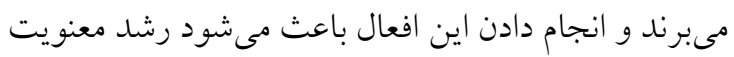

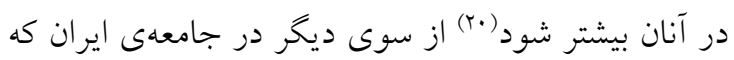

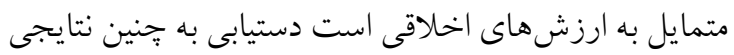
دور از انتظار نيست. از لحاظ ارتباط ما بين گروه سنى و سلامت معنوى نتايج مطالعه حاضر نشان داد كه با افزايش سن، سلامت معنوى لمنيى

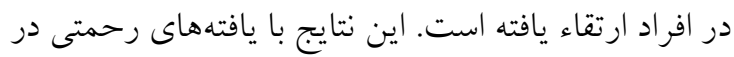

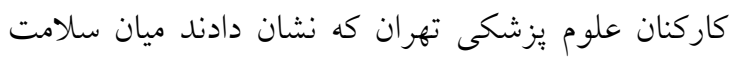
معنوى و سن ارتباط مثبتى وجود دارد(1) منطبق است. Rowe و Raczorowski عنوان مى كنند كه كشش به سوى معنويت عملكرد افزايش سن محسوب مىشود زيرا

\section{بحث و نتيجه كيرى}

در اين بزوهش نتايج نشان داد وضعيت سلامت معنوى در

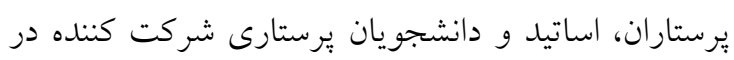

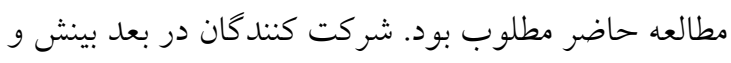

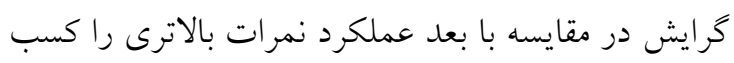

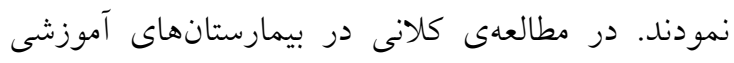

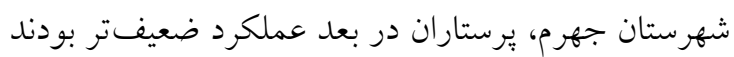

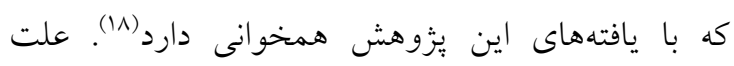

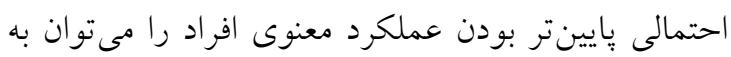
تنشهاى موجود در محيط حرفهاى مرتبط دانست. در

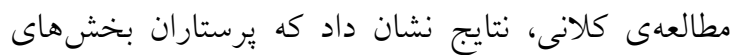
مراقبت ويزه، سلامت معنوى مطلوبى داشتند (1) كه با نتايج اين يُزوهش مطابقت دارد. در شهرستان جهرم پايبندى به عقايد مذهبى در زندكى مردم تبلور يافته و برخوردارى از

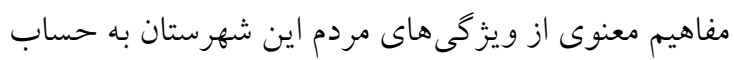

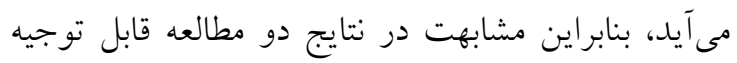

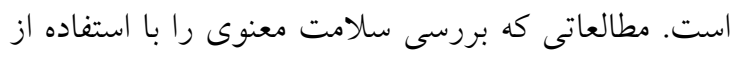
يرسشنامهى جامع سنجش سلامت معنوى در جامعه ايرانى

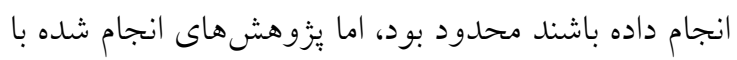

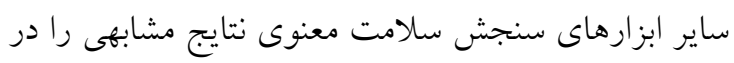

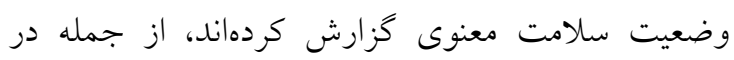

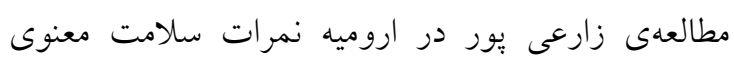

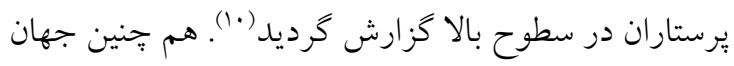

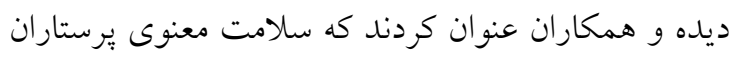
در بيمارستانهاى آموزشى شهر شيراز در سطح متوسط كرداند

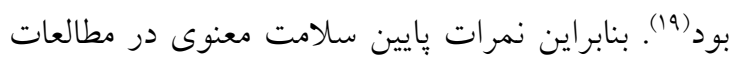

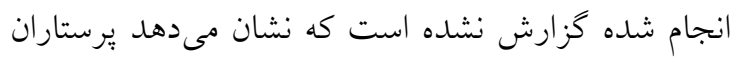

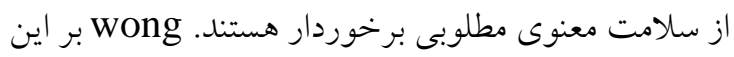
اعتقاد است كه يرستاران همواره به نيازهاى معنوى بيماران

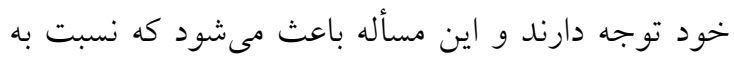

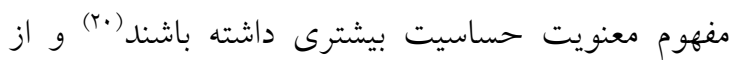
سلامت معنوى خوبى برخوردار باشند.

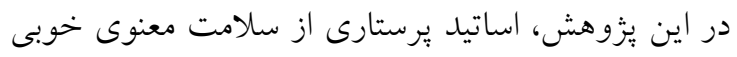
برخوردار بودند. بر اساس دانش محقق، گزارشى مبنى بر بر برى 
نتايج مطالعه حاضر نشان داد سلامت معنوى دانشجويانى كه در سال اول تحصيل بودند بالاتر از دانشجويان سال

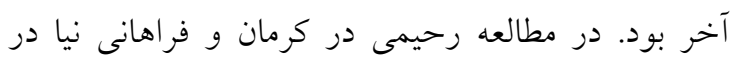

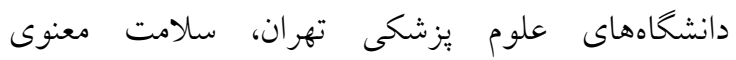
دانشجويان يرستارى سال جهارم در مقايسه با دانشجويان

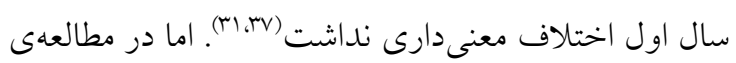
حاضر سلامت معنوى دانشجويان سال جهارم نسبت به دانشجويان سال اول كاهش يافته بود. علت عدم تغيير سلامت معنوى دانشجويان در مطالعات قبلى را به دليل خلأ مباحث مرتبط با معنويت در كوريكولوم رشته يرستارى

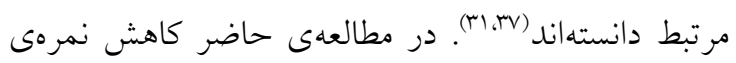

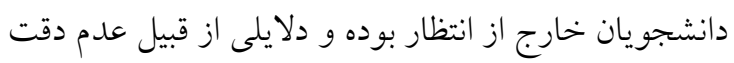

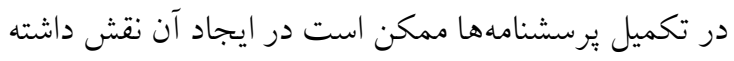
باشد. در مطالعات انجام شده ارتباط مثبت سلامت معنوى با اضطراب و سازكارى روانشناختى دانشجويان يُرستارى

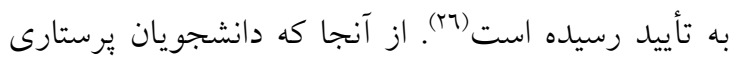

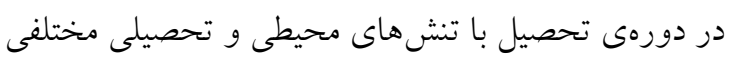

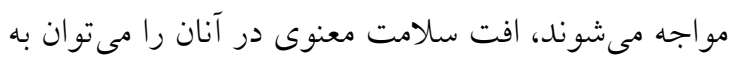

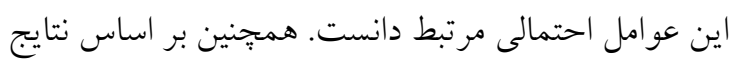

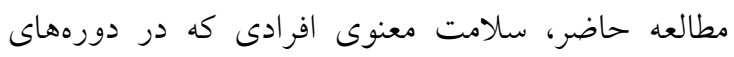

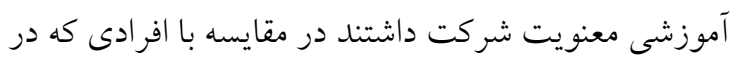

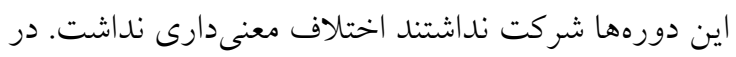
مطالعهى رحيمى در كرمان ميان نخرش معنوى دانشجويان

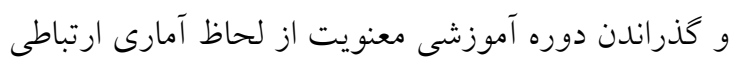
معنى دارى يافت نشد (rان).

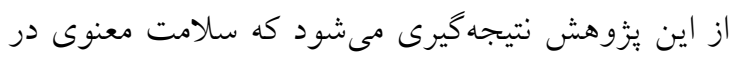
يرستاران، اساتيد و دانشجويان پرستارى از وضعيت مطلوبى برخوردار است. در شرايطى كه سلامت معنوى در ابعاد شخصى، حرفهاى و سازمانى براى برستاران سودمند

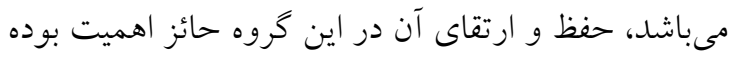
و شناخت عواملى كه بر سلامت معنوى آنان مؤثر هستند بايستى مورد توجه مسئولين قرار كيرد. با توجه به نتايج

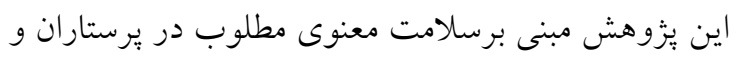
اساتيد يرستارى و ارتباط تنكاتنخ آنان با دانشجويان درس برستان
راهى است كه فرد توسط آن با واقعيت مرى روبرو مى شود (·rarr). در مطالعهى رحيمى در كرمان ارتباط معنى دارى توسط

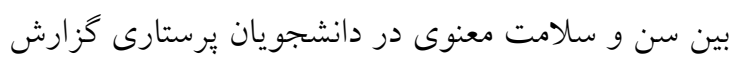

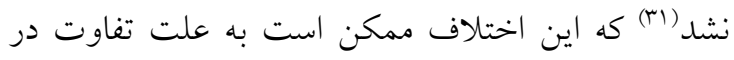
كروههاى مورد يزوهش باشد.

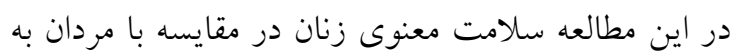

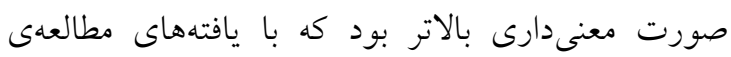

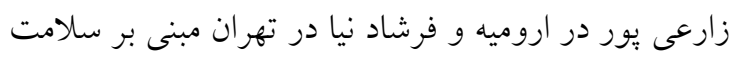

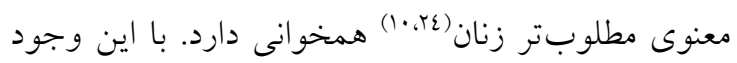

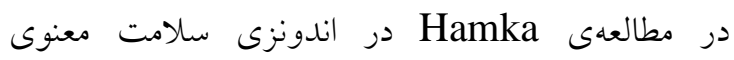

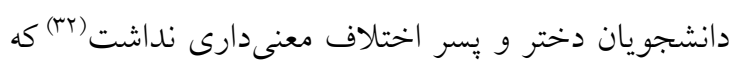

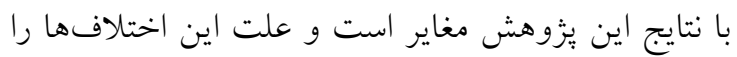
مىتوان در متفاوت بودن جامعلى يزووهش در دو مطالعه دانست. همجنين بر اساس نتايج مطالعه حاضر، سلامت معنوى در

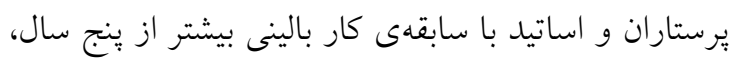

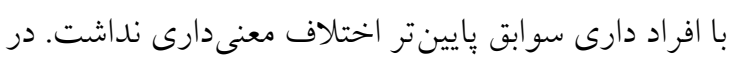

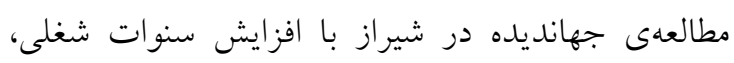

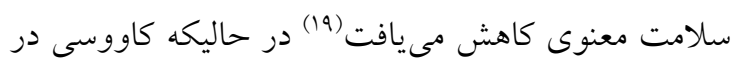

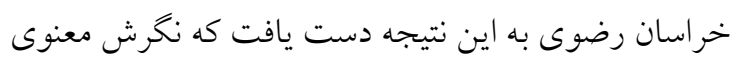

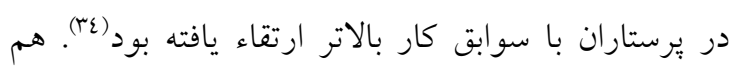
جنين در مطالعهى Wu در تايوان، نكرش معنوى يرستاران

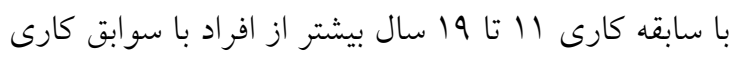

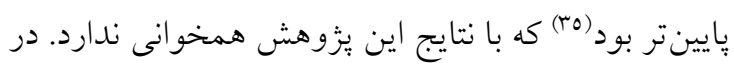

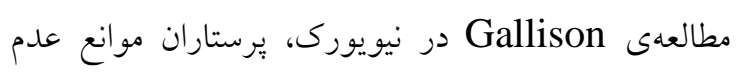

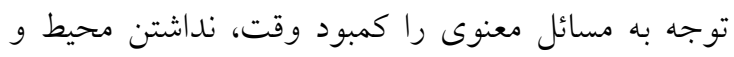

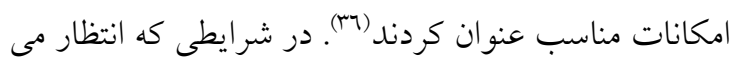
رسد با افزايش سوابق بالينى، سلامت معنوى در برستاران

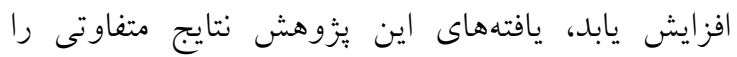

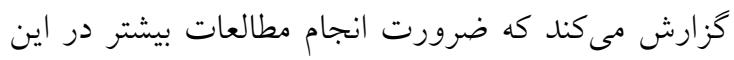

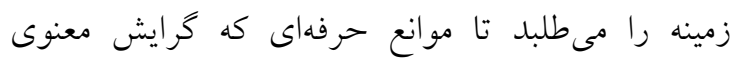
يرستاران را با افزايش سنوات خحمت تهلديد مى كند بيشتر

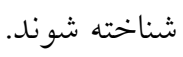




$$
\text { به نجام مطالعات گستردهتر درگروه اساتيد يرستارى با توجه العاتى موجود از اهميت بيشترى برخوردار }
$$

$$
\text { بيان نشارض منافع : هيج گونه تعارض منافع توسط نويسندكان }
$$

\section{تقدير و تشكر}

اين يُزوهش در قالب طرح تحقيقاتى در كميته اخلاق

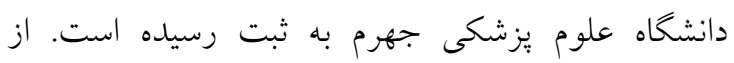

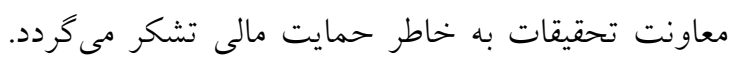

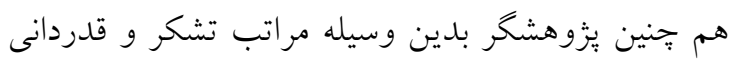

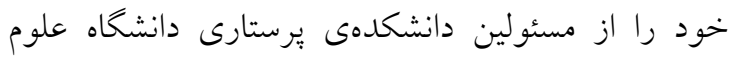

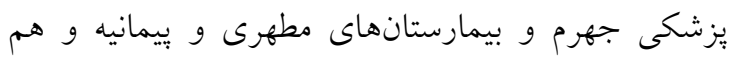

جنين يرستاران، اساتيد و دانشجويان شركت كننده در اين

$$
\text { يُزوهش و تمامى همر اهان ابراز مى دارد. }
$$

$$
\begin{aligned}
& \text { يرستارى در محيط بالين، توصيه مىشود برنامه ريزى لازم }
\end{aligned}
$$

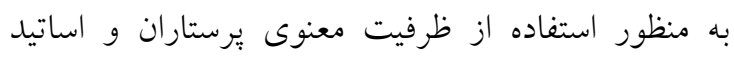

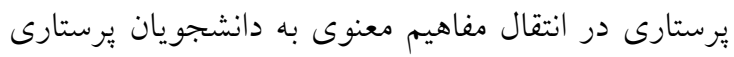

$$
\begin{aligned}
& \text { كه آينده سازان اين حرفه مىباشند انجام گيرد و و با ادغام }
\end{aligned}
$$

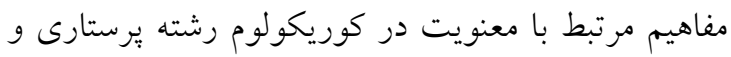

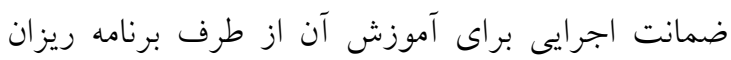

$$
\begin{aligned}
& \text { يرستارى و مديران اجرايى، امكان ارتقاى سلامت معنوى } \\
& \text { در دانشجويان يرستارى فراهم گردد. هم جنين دورههاى }
\end{aligned}
$$

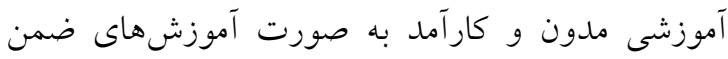

$$
\begin{aligned}
& \text { خدمت به منظور ارتقاى هر خهه بيشتر سلامت معنوى در }
\end{aligned}
$$

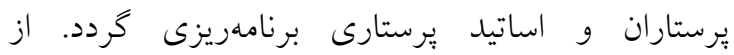

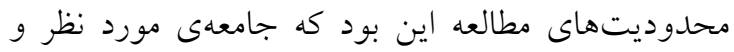

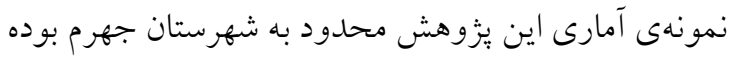

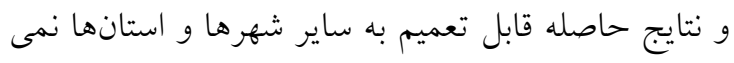

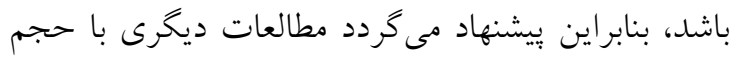

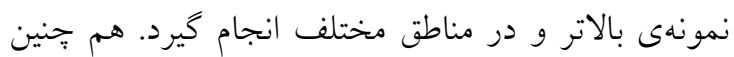

\section{References}

1. World Health Organization. International statistical classification of diseases and related health problems: Tabular list. World Health Organization; 2004.

2. Ross L, Giske T, Van Leeuwen R, Baldacchino D, McSherry W, Narayanasamy A, Jarvis P, Schep-Akkerman A. Factors contributing to student nurses'/midwives' perceived competency in spiritual care. Nurse Educ Today. 2016;36:445-51.

3. McSherry W. Making sense of spirituality in nursing and health care practice: An interactive approach. Jessica Kingsley Publishers; 2006.

4. Khorashadizadeh F, Heydari A, Heshmati Nabavi F, Mazlom SR, Ebrahimi M. Concept analysis of spiritual health based on Islamic teachings. Iran Journal of Nursing. 2015;28(97):42-55. [Persian]

5. Behboodi S, Abbasi M, Akrami F, Farid M, Akbari Kamrani M. Effectiveness of the Educational Intervention on Spiritual Health among Midwifery Students Using Iranian Comprehensive Questionnaire. Medical Ethics Journal( MEJ). 2019; 13(44): 1-9. [Persian]

6. Khalifi T, Seyedfatemi N, Mardani-Hamooleh M, Haghani H. The Effect of Spiritual Education on Spiritual Health of Nursing Students: A Quasi-Experimental study. Iranian Journal of Medical Ethics and History of Medicine. 2018;11(1):152-64. [Persian]

7. Ebadi BN, Hosseini MA, Rahgoi A, Fallahi Khoshknab M, Biglarian A. The relationship between spiritual health and happiness among nursing students. Journal of nursing education. 2017;5(5):23-30. [Persian]

8. Chiang YC, Lee HC, Chu TL, Han CY, Hsiao YC. The impact of nurses' spiritual health on their attitudes toward spiritual care, professional commitment, and caring. Nursing outlook. 2016;64(3):215-24.

9. Golipoor Khanmiri S, Khodaei A, Shirazi M, Naziri K. Evaluation of Association between Nurses' Spiritual Well-Being and Job Satisfaction in Educational-Therapeutic center Shohadaye Tabriz. Iranian Journal of Medical Ethics and History of Medicine. 2018;11(1):220-30. [Persian] 
10. Zareipour M, Rezaei ZM, Jafari F, Ghaderzadeh S. A study of the state of spiritual health and its relation to self-efficacy of nurses. Medical Science. 2020;24(101):407-14.

11. Saban RB, Villanueva MA, Nuqui C, Divina L, Mergal BB. Spiritual Health and Religious Practices as Correlates to the Quality of Life amongst Faculty and Staff. InAbstract Proceedings International Scholars Conference 2019;7(1): 447-65.

12. Hu Y, Jiao M, Li F. Effectiveness of spiritual care training to enhance spiritual health and spiritual care competency among oncology nurses. BMC palliative care. 2019;18(1):1-8.

13. Mohammadi S, Soleymanpoor L, Borhani F, Roshanzadeh M. Spiritual Intelligence and Spiritual Wellbeing in the Students of a Nursing College. Iran Journal of Nursing (IJN). 2018;31(113):1-9. [Persian]

14. Heshmati-Nabavi F, Vanaki Z. Professional approach: The key feature of effective clinical educator in Iran. Nurse Educ Today. 2010;30(2):163-8.

15. Lee Y. The relationship of spiritual well-being and involvement with depression and perceived stress in Korean nursing students. Global journal of health science. 2014;6(4):169-76.

16. Nasrollahi Z, Eskandari N, Adaryani MR, Tasuji MH. Spirituality and effective factors in education: A qualitative study. J Educ Health Prom. 2020;9(52).1-22.

17. Amiri P, Abbasi M, Gharibzadeh S, Asghari JM, Hamzavi ZN, Azizi F. Designation and psychometric assessment of a comprehensive spiritual health questionnaire for Iranian populations. Medical Ethic Quarterly. 2014;8(30):49-54. [Persian]

18. Kalani N, Javadpour S, Jamali S, Amininejad T, Dolatkhah HR, Rayat Dost E. Assessing the spiritual health in nurses of critical care units: A cross-sectional study. J Glob Pharma Technol. 2016;3(8):30-5.

19. Jahandideh S, Zare A, Kendall E, Jahandideh M. Nurses' spiritual well-being and patients' spiritual care in Iran. COJ Nurse Healthcare. 2018;1(3):1-5.

20. WONG WF, LUK AL. A Randomized Control Study on the Effectiveness of Holistic Health Practice Program on a Group of Baccalaureate Nursing Students. Open Nurs J. 2020 23;14(1):5663.

21. Linda NS, Phetlhu DR, Klopper HC. Nurse educators' understanding of spirituality and spiritual care in nursing: A South African perspective (Part 1). Int J Africa Nurs Sci. 2020;12:100-87.

22. Mokhtari Noori J, Ebadi A, Alhani F, Rejeh N. Spirituality-based education by role model nursing instructors: a qualitative study. Iranian Journal of Medical Ethics and History of Medicine. 2013;6(3):84-93. [Persian]

23. Momennasab M, Shadfard Z, Jaberi A, Najafi SS, Hosseini FN. The Effect of Group Reflection on Nursing Students' Spiritual Well-being and Attitude Toward Spiritual Care: a randomized controlled trial. Investigacion y educacion en enfermeria. 2019;37(1):80-9.

24. Farshadnia E, Borji M, Sadighpour M, Khorrami Z, Memaryan N. The Role of Demographic Factors in the Spiritual Health of the Students of Iran University of Medical Sciences. Int J Behav Sci. 2020;14(1):1-5. [Persian]

25. Aramideh A, Darabinia M, Afkahaminia F, Pahnabi A, Siamian H. Relationship between spiritual health and achievement motivation among students of Mazandaran University of Medical Sciences. Journal of Religion and Health. 2018;5(2):50-7. [Persian]

26. Shamsizadeh M, Oshvandi K, Moamer S, Maghsoudi Z. The Relationship Between Spiritual Health and Moral Sensitivity in Nursing Students of Hamadan University of Medical Sciences, 2017. Avicenna Journal of Nursing and Midwifery Care. 2020;28(2):75-82. [Persian]

27. Hsiao YC, Chiang HY, Chien LY. An exploration of the status of spiritual health among nursing students in Taiwan. Nurse Educ Today. 2010;30(5):386-92.

28. Najarkolaei FR, Haghighi M, Heydarabadi AB, Ansarian A, Mesri M. Investigation of spiritual health in staff of one Medical Sciences University in Tehran. Journal of Pizhūhish dar dīn va salāmat. 2015;1(1):13-20. [Persian]

29. Rowe MM, Allen RG. Spirituality as a means of coping with chronic illness. Am J Health Stud. 2004;19(1):62-7.

30. Kaczorowski JM. Spiritual well-being and anxiety in adults diagnosed with cancer. The Hospice Journal. 1989;5(3-4):105-16.

31. Rahimi N, Nouhi E, Nakhaee N. Spiritual well-being and attitude toward spirituality and spiritual care in nursing and midwifery students. Iran Journal of nursing. 2013;26(85):55-65. [Persian] 
32. Mein-Woei S. Spiritual Well-Being and Mental Health of Students in Indonesia. In $5^{\text {th }}$ ASEAN Conference on Psychology, Counselling, and Humanities (ACPCH 2019) 2020 Jan 22:149-52. Atlantis Press.

33. Mardani Hamooleh M, Seyedfatemi N, Eslami A, Haghani SH. The Spiritual Care Competency of the Nurses of the Teaching Hospitals Affiliated to Alborz University of Medical Sciences, Iran. Iran Journal of Nursing. 2020;33(124):58-69. [Persian]

34. Kavosi A, Taghiabadi M, Mohammadi G, Yazdi K, Shirdelzadeh S, Nasiri H, Roohi G, Shariati A, Rahmani H, Mollaei E, Aryaeefar M. Nursing managers attitude toward spirituality and spiritual care in Khorasan Razavi Province hospitals in 2016. Electronic physician. 2018;10(3):6571-6.

35. Wu LF, Lin LY. Exploration of clinical nurses' perceptions of spirituality and spiritual care. $J$ Nurs Res. 2011;19(4):250-6.

36. Gallison BS, Xu Y, Jurgens CY, Boyle SM. Acute care nurses' spiritual care practices. J Holis Nurs. 2013;31(2):95-103.

37. Farahaninia M, Abbasi M, Givari A, Haghani H. Nursing students' spiritual well-being and their perspectives towards spirituality and spiritual care perspectives. Iran Journal of Nursing. 2006;18(44):7-14. [Persian] 